\title{
Parameters Influencing Sulfur Speciation in Environmental Samples Using Sulfur K-Edge X-Ray Absorption Near-Edge Structure
}

\author{
Siwatt Pongpiachan, ${ }^{1}$ Kanjana Thumanu, ${ }^{2}$ Charnwit Kositanont, ${ }^{3}$ Klaus Schwarzer, ${ }^{4}$ \\ Jörg Prietzel, ${ }^{5}$ Phoosak Hirunyatrakul, ${ }^{6}$ and Itthipon Kittikoon ${ }^{6}$
}

${ }^{1}$ NIDA Center for Research \& Development of Disaster Prevention \& Management, School of Social and Environmental Development, National Institute of Development Administration (NIDA), 118 Moo 3, Sereethai Road, Klong-Chan, Bangkapi, Bangkok 10240, Thailand

${ }^{2}$ Synchrotron Light Research Institute (Public Organization), 111 University Avenue, P.O. Box 93, Nakhon Ratchasima 30000, Thailand

${ }^{3}$ Inter-Department of Environmental Science, Faculty of Graduate Studies, Chulalongkorn University, Bangkok 10330, Thailand

${ }^{4}$ Institute of Geosciences Sedimentology, Coastal and Continental Shelf Research, Otto-Hahn-Platz 1, 24118 Kiel, Germany

${ }^{5}$ Lehrstuhl für Bodenkunde, Technische Universität München, Weihenstephan 85350 Freising, Germany

${ }^{6}$ Bara Scientific Co., Ltd., 968 Rama 4 Silom Bangrak, Bangkok 10500, Thailand

Correspondence should be addressed to Siwatt Pongpiachan, pongpiajun@gmail.com

Received 23 May 2012; Revised 9 August 2012; Accepted 19 September 2012

Academic Editor: Ki-Hyun Kim

Copyright ( 2012 Siwatt Pongpiachan et al. This is an open access article distributed under the Creative Commons Attribution License, which permits unrestricted use, distribution, and reproduction in any medium, provided the original work is properly cited.

This paper aims to enhance the credibility of applying the sulfur K-edge XANES spectroscopy as an innovative "fingerprint" for characterizing environmental samples. The sensitivities of sulfur K-edge XANES spectra of ten sulfur compound standards detected by two different detectors, namely, Lytle detector (LyD) and Germanium detector (GeD), were studied and compared. Further investigation on "self-absorption" effect revealed that the maximum sensitivities of sulfur K-edge XANES spectra were achieved when diluting sulfur compound standards with boron nitride (BN) at the mixing ratio of $0.1 \%$. The "particle-size" effect on sulfur K-edge XANES spectrum sensitivities was examined by comparing signal-to-noise ratios of total suspended particles (TSP) and particulate matter of less than 10 millionths of a meter $\left(\mathrm{PM}_{10}\right)$ collected at three major cities of Thailand. The analytical results have demonstrated that the signal-to-noise ratios of sulfur K-edge XANES spectra were positively correlated with sulfate content in aerosols and negatively connected with particle sizes. The combination of hierarchical cluster analysis (HCA) and principal component analysis (PCA) has proved that sulfur K-edge XANES spectrum can be used to characterize German terrestrial soils and Andaman coastal sediments. In addition, this study highlighted the capability of sulfur K-edge XANES spectra as an innovative "fingerprint" to distinguish tsunami backwash deposits (TBD) from typical marine sediments (TMS).

\section{Introduction}

During the past decades, considerable research has been intensively focused on the topic of sulfur speciation in the environment. It has become more evident that the plant uptake availability [1] and climate forcing capability [2,3] of sulfur compounds depend not purely on their concentrations but, severely, on the chemical forms in which they exist in natural compartments. Furthermore, ammonium salts such as ammonium chloride $\left(\mathrm{NH}_{4} \mathrm{Cl}\right)$, ammonium nitrate $\left(\mathrm{NH}_{4} \mathrm{NO}_{3}\right)$, ammonium sulfate $\left(\left(\mathrm{NH}_{4}\right)_{2} \mathrm{SO}_{4}\right)$, and bisulfate
$\left(\mathrm{NH}_{4} \mathrm{HSO}_{4}\right)$ are widely considered as acidic aerosols and may have been responsible for the acid rain in pristine area $[4,5]$. Hence, information on the chemical state of sulfur in aerosol is important from the viewpoint of environmental science, in order to study the origins of the acid rain and the causes of climate change.

Continuing developments in various atomic spectrochemical techniques enable researchers to extract some useful information related to the physicochemical properties of sulfur contents in atmospheric aerosols. For instance, the chemical speciation of sulfate aerosols collected weekly for a 
one-year period in Matsue, Shimane prefecture, Japan, was investigated by X-ray powder diffraction (XRD) [6]. It is also important to note that X-ray photoelectron spectroscopy (XPS) has been widely employed to determine the surface composition and structure of sulfur in aerosols collected at Salt Lake city [7], Jinan city of China [8], and four towns in southern Poland [9]. Although XPS provides insight into the elemental composition, empirical formula, chemical state, and electronic state of sulfur on surface aerosol, this quantitative spectroscopic technique requires not only ultra high vacuum (UHV) condition but also a considerable amount of aerosol loading on the filter. Furthermore, it is not practical to use XRD to measure the chemical state of sulfur in amorphous or poorly crystalline particle such as atmospheric aerosol.

Recent research has found that X-ray absorption nearedge structure (XANES) can be used to determine the oxidation state of sulfur compounds even in the case of aerosol samples, which usually exist in trace levels. This innovative approach presents the potential for elucidating the very complicated chemical forms of sulfur in the natural environment. It is well known that fluorescent mode XANES (FL-XANES) is the most suitable method applied to dilute samples where "self-absorption effect" (i.e., the fluorescence X-ray signals are attenuated by reabsorption of absorber atoms in the sample) is often considered of major importance. Unlike transmission mode XANES (TMXANES), which requires sample having $\mathrm{X}$-ray absorbing atoms at high density ( $>5 \% \mathrm{wt})$, only small amount of sample is sufficient to be detected in FL-XANES. Therefore, it seems logical to conduct sulfur speciation measurement of environmental sample in FL-XANES. However, some critical facts have been identified and need to be investigated with great caution.

Since the fluorescence excitation spectra detected by FL-XANES are more susceptible to various extraneous factors in the beam path, it is therefore crucial to estimate the signal-to-noise $(\mathrm{S} / \mathrm{N})$ ratio of target sulfur compound measured in different types of fluorescence detectors such as Germanium detector (GeD) and Lytle detector (LyD). Although the relationship between the $\mathrm{S} / \mathrm{N}$ ratio of sulfur $\mathrm{K}$-edge XANES spectra and the grain size was previously investigated [10], little is known about the impact of "grain size effect" on spectra absorption in aerosol sample. In addition, the availability of using sulfur speciation as a new proxy to discriminate "typical marine sediment" and "tsunami backwash deposit" will be carefully investigated. The overall aims of this study are the following.

(1) To investigate the impact of $\mathrm{GeD}$ and $\mathrm{LyD}$ on $\mathrm{S} / \mathrm{N}$ ratio of sulfur K-edge XANES spectra of ammonium sulfate $\left(\left(\mathrm{NH}_{4}\right)_{2} \mathrm{SO}_{4}\right)$, calcium sulfate $\left(\mathrm{CaSO}_{4}\right)$, aluminium sulfate $\left(\mathrm{Al}_{2}\left(\mathrm{SO}_{4}\right)_{3}\right)$, manganese sulfate $\left(\mathrm{MnSO}_{4}\right)$, zinc sulfate $\left(\mathrm{ZnSO}_{4} \cdot 7 \mathrm{H}_{2} \mathrm{O}\right)$, potassium thiosulfate $\left(\mathrm{K}_{2} \mathrm{~S}_{2} \mathrm{O}_{3}\right)$, chromic sulfate $\left(\mathrm{Cr}_{2}\left(\mathrm{SO}_{4}\right)_{3} \cdot 15 \mathrm{H}_{2} \mathrm{O}\right)$, cobalt sulfate $\left(\mathrm{CoSO}_{4} \cdot 7 \mathrm{H}_{2} \mathrm{O}\right)$, nickel sulfate $\left(\mathrm{NiSO}_{4} \cdot 6 \mathrm{H}_{2} \mathrm{O}\right)$, and copper sulfate $\left(\mathrm{CuSO}_{4} \cdot 5 \mathrm{H}_{2} \mathrm{O}\right)$ including the self-absorption effects in FL-XANES.
(2) To conduct the statistical investigation of "grain size effect" on sulfur K-edge XANES spectra sensitivity in total suspended particle (TSP) and particle with diameter less than or equal to 10 microns (PM10) collected at the urban sampling sites of Bangkok, Chiang-Mai, and Hat-Yai, Thailand.

(3) To evaluate the variation of sulfur speciation in both "typical marine sediments (TMS)" and "tsunami backwash deposits (TBD)" collected at the 2004 tsunami-affected coastal areas of Andaman Sea, Thailand.

\section{Materials and Methods}

2.1. Sample Collection and Sampling Site Descriptions. Ambient air samples were collected over periods of $6 \mathrm{~h}$ (09:0015:00) using a Graseby-Andersen high volume air sampler with TSP and $\mathrm{PM}_{10}$ TE-6001, operating at the flow rate of $1.4 \mathrm{~m}^{3} \mathrm{~min}^{-1}$. TSP and $\mathrm{PM}_{10}$ were collected on $47 \mathrm{~mm}$ Whatman quartz microfiber filters (QM/A). The filters were preheated at $800^{\circ} \mathrm{C}$ for $12 \mathrm{~h}$ prior to sampling. The exposed filters were stored in a refrigerator at about $4^{\circ} \mathrm{C}$ until sulfur speciation analysis to prevent the evaporation of volatile compounds. All the field sampling and filters weighing were performed in compliance with the US EPA's guideline of standard operating procedure for sampling and handling of $\mathrm{PM}_{2.5}$ filters. It is important to note that all filters were weighed by Mettler Toledo AB204-S Analytical Balance before sending to Synchrotron Light Research Institute (Public Organization), Thailand. All the three sampling sites are located in the city center of Bangkok, ChiangMai, and Hat-Yai, representing the capital, the largest cities in northern and southern regions of Thailand, respectively (Table 1). Air samples were collected above the ground level at Bai-Yok Suit Hotel Observatory Site in February 18-21, 2008, at Centara Duangtawan Hotel Observatory Site in February 25-28, 2008 and at Novotel Centara Hat-Yai Hotel Observatory Site in December 17-20, 2007 as monitoring sites for Bangkok, Chiang-Mai, and Hat-Yai in that order. It is well known that traffic emissions are considered as main sources of air pollutants in Bangkok atmosphere, whilst agricultural burnings are major air pollution problems in Chiang-Mai. Furthermore, Hat-Yai is located only $30 \mathrm{~km}$ at the west of the Gulf of Thailand. Thus, one can safely assume that aerosol samples used in this study may consist of traffic aerosols with the mixture of industrial exhausts, biomass burning, and sea salt aerosols in the case of Bangkok, ChiangMai, and Hat-Yai, respectively.

Sediment sample collection was carried out offshore along the west coast of Phang Nga province, Thailand, which was heavily affected by the 2004 tsunami [11]. The research area covers approximately $1,000 \mathrm{~km}^{2}$ between Thap Lamu and Pakarang Cape, up to a water depth of 70 meters. During the research cruises in November-December 2007 with RV Chakratong Tongyai, approximately 1,500 nautical miles of hydroacoustic profiles (side scan sonar, multibeam echo sounder and shallow reflection seismics with a boomer system) were recorded at the front of 


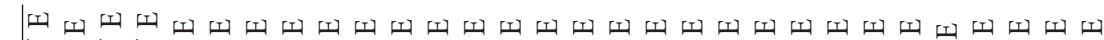

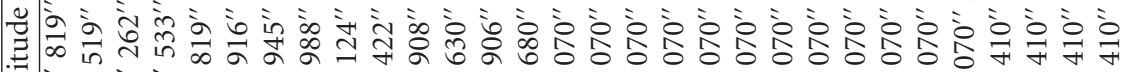

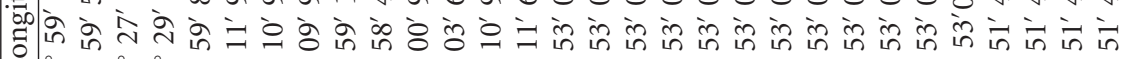

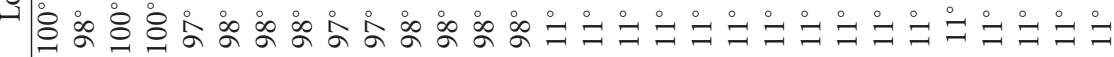
ZZZZZZZZZZZZZZZZZZZZZZZZZZZZZZ

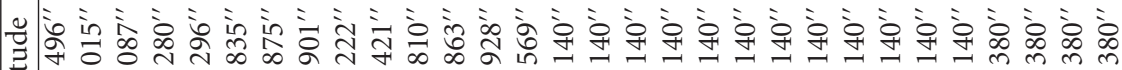

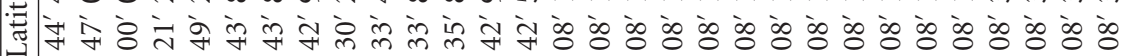
记 옹

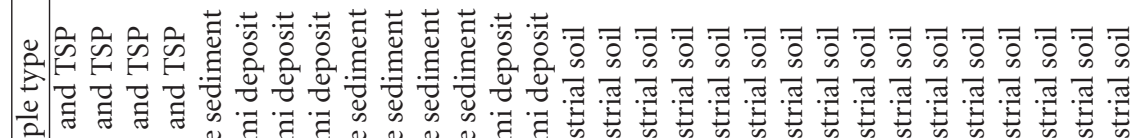

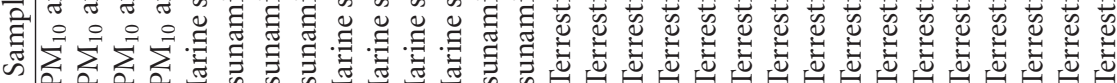

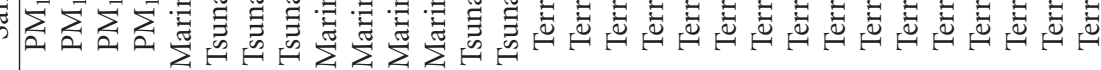

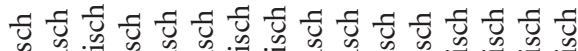

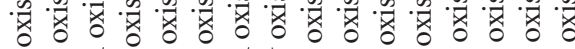

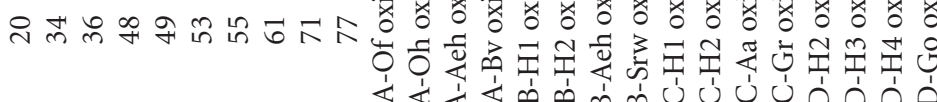

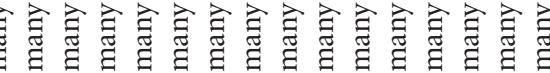

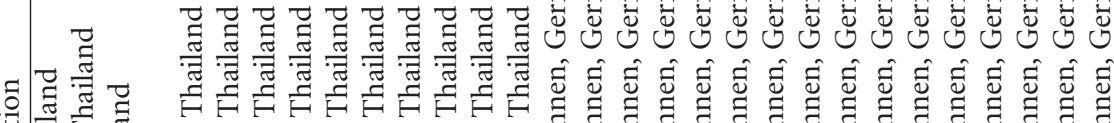

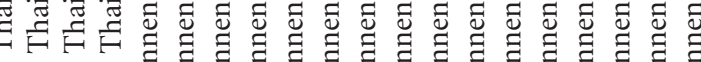
6.0

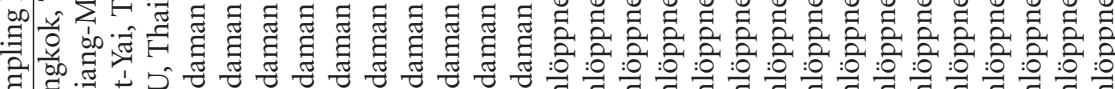

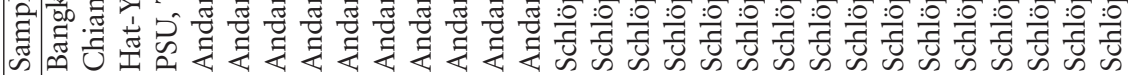


Pakarang Cape. In this study, two types of coastal sediments, namely, "tsunami deposit" and "typical marine sediment" were carefully identified based on previous geophysical information [10]. The sediment samples were taken with a Van-Veen-type grab sampler. Soil samples were collected from four locations at two different sites in the Lehstenbach watershed (Fichtelgebirge, Germany). In this study, three different types of terrestrial soils, namely, Endostagnic Leptic Cambisol (alumic), Histic Stagnosol (albic, alumic), and Leptic Rheic Hemic Histosol (dystric) were used for the analysis of sulfur K-edge XANES spectra for comparison purpose. Since the soil types and sampling sites have been described in detail in previous publication [12], therefore only a short summary is provided here.

2.2. Sulfur K-Edge XANES Experiment. XANES of the samples and standards were measured at the beamline No. 8 at the Siam Photon Laboratory [13]. Photon energy of an Xray beam transported through the beamline was scanned by InSb(111) double crystals equipped in the monochromator. The beam size illuminating the sample was $10 \mathrm{~mm}(\mathrm{w}) \times$ $1 \mathrm{~mm}$ (h). A $10 \mathrm{~cm}$ long ion chamber filled with a gas mixture of $\mathrm{N}_{2}$ (30 mbar) and $\mathrm{He}(983$ mbar) was employed to measure intensity of the X-ray beam. The ion chamber absorbed only $10 \%$ of the beam intensity for ionization of the filling gas and produced small electrical current signal proportional to the beam intensity.

Fluorescence X-rays were emitted from the sample and collected by either a 13-channel Germanium detector (GeD) or a Lytle detector (LyD). The GeD has advantage over the LyD in discrimination of X-ray fluorescence energy. With the use of a digital window, only $\mathrm{K}_{\alpha}$ photons from sulfur were counted. The final photon counts were averaged over all the channels. Similar to the ion chamber, the LyD produces small electrical current signal corresponding not only to fluorescence X-rays from sulfur but other elements present in the sample and the scattered photons from the primary beam. The sample chamber was flowed in with He gas to reduce X-ray absorption and scattering by air. A thin polypropylene window was required to protect the GeD from He gas, which can diffuse through thin detector seal of beryllium spoiling cryostat vacuum of the detector. A minimum air gap of $5 \mathrm{~mm}$ was introduced for detector clearance. The distances from the sample to detector were $7 \mathrm{~mm}$ and $9 \mathrm{~mm}$ for GeD and LyD, respectively. XANES spectra were recorded from $2450 \mathrm{eV}$ to $2520 \mathrm{eV}$ with the energy step of $0.2 \mathrm{eV}$ and energycalibrated using the maximum absorption of iron sulfate at $2481.4 \mathrm{eV}$ [14]. In addition the resolving power (E/DE) is 10,000 . Absorbance was calculated by the ratio of photon counts from the fluorescent detector to the ion chamber.

For sensitivity test $\left(\mathrm{NH}_{4}\right)_{2} \mathrm{SO}_{4}, \mathrm{CaSO}_{4}, \mathrm{Al}_{2}\left(\mathrm{SO}_{4}\right)_{3}$, $\mathrm{MnSO}_{4}, \quad \mathrm{ZnSO}_{4} \cdot 7 \mathrm{H}_{2} \mathrm{O}, \quad \mathrm{K}_{2} \mathrm{~S}_{2} \mathrm{O}_{3}, \quad \mathrm{Cr}_{2}\left(\mathrm{SO}_{4}\right)_{3} \cdot 15 \mathrm{H}_{2} \mathrm{O}$, $\mathrm{CoSO}_{4} \cdot 7 \mathrm{H}_{2} \mathrm{O}, \mathrm{NiSO}_{4} \cdot 6 \mathrm{H}_{2} \mathrm{O}$, and $\mathrm{CuSO}_{4} \cdot 5 \mathrm{H}_{2} \mathrm{O}$ were diluted by physically mixing with boron nitride $(\mathrm{BN})$ with the mixing ratios (standard: $\mathrm{BN}$ in percentage) of $0.1 \%, 1.0 \%$, $10.0 \%$, and $100 \%$. The dilute standards were applied on adhesive side of the polyimide tape and placed at $45^{\circ} \mathrm{C}$ to the beam path in the sample chamber. Without dilution, similar approach was used for the preparation of environmental samples. The data processing and quantitative XANES analyses were conducted by ATHENA program in the IFEFFIT computer package [15]. In this study, SNR (signalto-noise ratio) was employed to characterize the sensitivity of S-K-edge XANES spectra. "Noise" was calculated by using the standard deviation of peak intensities of preedge region (i.e., 2,450-2,475 eV), whilst the definition of "signal" was termed as the difference between main peak at 2,482 eV and the average peak intensity of preedge region (i.e., baseline).

2.3. Determination of Water Soluble Ionic Species (WSIS) in Aerosol Samples. All filter samples were stored in a refrigerator at about $4^{\circ} \mathrm{C}$ as soon as possible after sampling was completed. This was necessary to prevent any negative artifacts caused by losses of semivolatile compounds. Also field blank filters were collected to subtract the positive artifacts due to adsorption of gas phase organic compounds onto the filter during and/or after sampling. The analysis of water soluble ionic species (WSIS) including cation $\left(\mathrm{Na}^{+}, \mathrm{NH}_{4}{ }^{+}, \mathrm{K}^{+}, \mathrm{Ca}^{2+}\right)$ and anion $\left(\mathrm{Cl}^{-}, \mathrm{NO}_{3}{ }^{-}, \mathrm{SO}_{4}{ }^{2-}\right)$ was performed by using Metrohm Ion Chromatography (IC) analyzer with the combination of IC 818 pump, IC 819 detector, IC 830 advance interface, and IC 833 Advanced IC Liquid Handling Pump Unit-two-channel peristaltic pump for use with the Metrohm Suppressor Module (MSM).

Metrosep A Supp 16-250 and Metrosep C 4-250 columns were employed for the analysis of anion and cation species, respectively. Filters were cut, placed in a polyethylene vial $(50 \mathrm{~mL})$, and extracted with $10 \mathrm{~mL}$ of Milli-Q water for $30 \mathrm{~min}$. The extract was filtered through $0.2 \mu \mathrm{m}$ pore size Millipore Teflon filters for cleanup. In addition, standard solutions were purchased from Fuka (Multielement Ion chromatography: number 89886.0050 and No.89316.0050 and Ammonium ion standard solution: number 09685.0250).

\section{Results and Discussion}

Ten sulfur compound standards, six aerosols, ten marine sediments, and five urban soils were analyzed by XANES in fluorescence mode detected with two different detectors. Generally, XANES can be measured in three different ways, namely, transmission, fluorescence, and electron yield modes. These three modes are widely adopted depending upon purposes. For instances, the scanning transmission Xray microscope can be applied for imaging various biological as well as polymer samples at $55 \mathrm{~nm}$ Rayleigh resolution, whilst the fluorescent mode can be used for measuring $\mathrm{X}$ ray absorption spectra of crystalline $(c)-\mathrm{Si}-\mathrm{C}-\mathrm{N}$ thin film $[16,17]$.

In the case of conventional transmission mode, the intensity of the monochromatic X-ray incident is detected before $\left(\mathrm{I}_{0}\right)$ and after processing through the target sample $\left(\mathrm{I}_{n}\right)$ employing ion chamber gas detectors. As a consequence, the XANES spectrum will then demonstrate the oscillation of $\log \left(\mathrm{I}_{0} / \mathrm{I}_{n}\right)$ versus energy $(\mathrm{eV})$. Whilst it is widely accepted that the transmission mode is suitable for those 
"high density thin layer" type sample, the electron yield mode coupled with total external reflection fluorescence is generally considered as the most appropriate detector for analyzing those "high density high layer" type sample. It is also important to stress that the fluorescence detector has the greatest advantage to apply with those dilute, relatively low K-edge energies, and small samples [16]. Furthermore, a recent study reveals that the combination of high-purity Germanium (HPGe) detector and fluorescence mode can combat various analytical difficulties such as the complex signal processing electronics and limitation of sample size and amount [17]. Thus, it seems logical to apply fluorescence mode for overcoming the problems of limited sample loading with typical high-matrix containing such as environmental samples.

3.1. Comparison of Sensitivity Test between $\mathrm{GeD}$ and LyD. The sulfur K-edge XANES spectra for $\left(\mathrm{NH}_{4}\right)_{2} \mathrm{SO}_{4}$, $\mathrm{CaSO}_{4}, \quad \mathrm{Al}_{2}\left(\mathrm{SO}_{4}\right)_{3}, \quad \mathrm{MnSO}_{4}, \quad \mathrm{ZnSO}_{4} \cdot 7 \mathrm{H}_{2} \mathrm{O}, \quad \mathrm{K}_{2} \mathrm{~S}_{2} \mathrm{O}_{3}$, $\mathrm{Cr}_{2}\left(\mathrm{SO}_{4}\right)_{3} \cdot 15 \mathrm{H}_{2} \mathrm{O}, \quad \mathrm{CoSO}_{4} \cdot 7 \mathrm{H}_{2} \mathrm{O}, \quad \mathrm{NiSO}_{4} \cdot 6 \mathrm{H}_{2} \mathrm{O}, \quad$ and $\mathrm{CuSO}_{4} \cdot 5 \mathrm{H}_{2} \mathrm{O}$ exhibited the main peak at $2,482 \mathrm{eV}$ for both detectors. The degree of reproducibility of main peak was relatively stable within $\pm 0.3 \mathrm{eV}$ for various sulfate compounds and also consistent with other previous studies of sulfur speciation $[18,19]$. For this reason it appears difficult to utilize the energy level to characterize each sulfate compounds. However, there were some differences among sulfur K-edge XANES spectra observed in the postedge region between 2,482 and 2,500 eV as displayed in Figure 1 . It is likely that the change in subsequent structure must be ascribed to electron transitions with a d-type shape resonance, which is dependent on cation type associated with sulfate ions $[20,21]$. The obvious difference in the sulfur K-edge XANES spectrum between $\mathrm{K}_{2} \mathrm{~S}_{2} \mathrm{O}_{3}$ and other sulfate compounds might reflect the level of oxidation state dissimilarity.

A crucial caution for fluorescence measurements is the selection of detector types to use in the ion chamber. In general, it is desirable to adopt LyD for measuring samples with relatively high ion count rate due to its much larger solid angle of acceptance in comparison with those of $\mathrm{GeD}$. On the contrary, it is preferable to use $\mathrm{GeD}$ for detecting more dilute elements in samples as a consequence of recent improvement in crystallographic properties, enhancement in purity concentrations with larger axial uniformity, and enlargement in detector size $[22,23]$. Additionally, the electron yield mode is often used for bulk and surface-sensitive analysis [24]. In practice, however, there are many factors that may undermine the sensitivity of XANES spectrum measured by GeD. Several authors have raised concerns on significant damping of XANES spectra of standard samples caused by self-absorption effects $[25,26]$. In order to minimize this effect, it is often necessary to blend sample with an inert matrix such as $\mathrm{BN}$ to increase the $\mathrm{S} / \mathrm{N}$ ratio. Generally, XANES spectra of ten sulfur compounds indicated that better sensitivity could be achieved in both detectors with mixing ratios of standard to $\mathrm{BN}$ at $0.1 \%$ (Table 2). Whilst the two detectors generated similar sensitivity for XANES spectra of $\left(\mathrm{NH}_{4}\right)_{2} \mathrm{SO}_{4}, \mathrm{CaSO}_{4}, \mathrm{Al}_{2}\left(\mathrm{SO}_{4}\right)_{3}$,

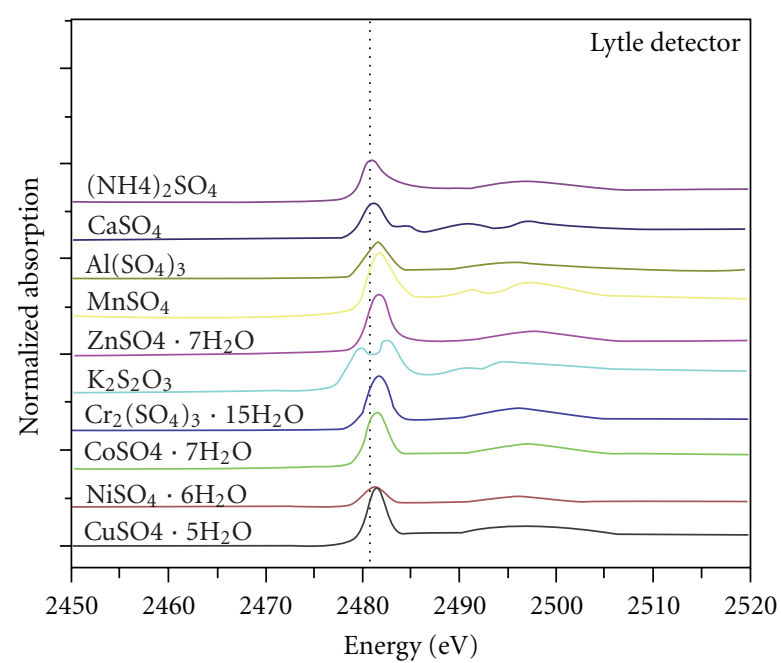

(a)

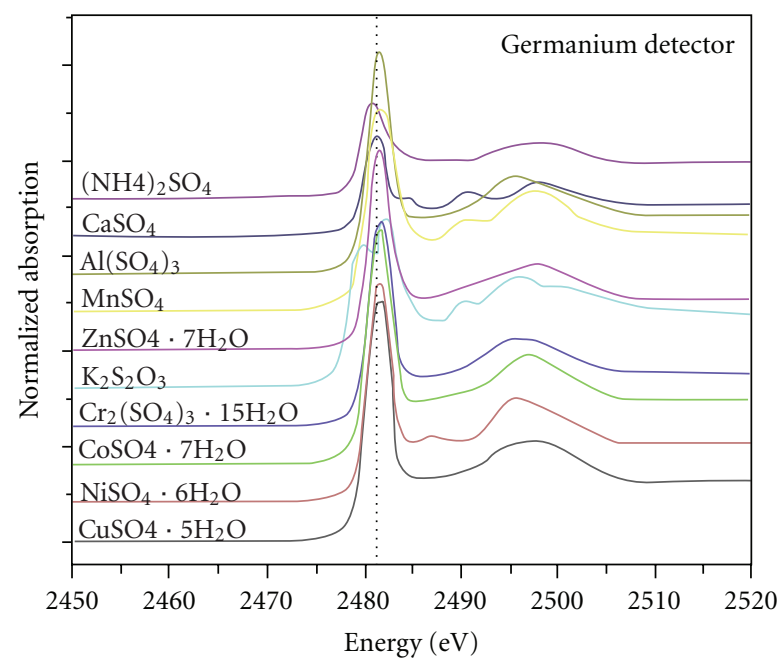

(b)

Figure 1: Normalized XANES spectra at sulfur K-edge spectra for $\left(\mathrm{NH}_{4}\right)_{2} \mathrm{SO}_{4}, \mathrm{CaSO}_{4}, \mathrm{Al}\left(\mathrm{SO}_{4}\right)_{3}, \mathrm{MnSO}_{4}, \mathrm{ZnSO}_{4} * 7 \mathrm{H}_{2} \mathrm{O}$, $\mathrm{K}_{2} \mathrm{~S}_{2} \mathrm{O}_{3}, \mathrm{Cr}_{2}\left(\mathrm{SO}_{4}\right)_{3} * 15 \mathrm{H}_{2} \mathrm{O}, \mathrm{CoSO}_{4} * 7 \mathrm{H}_{2} \mathrm{O}, \mathrm{NiSO}_{4} * 6 \mathrm{H}_{2} \mathrm{O}$, and $\mathrm{CuSO}_{4} * 5 \mathrm{H}_{2} \mathrm{O}$ measured by Germanium and Lytle detectors.

$\mathrm{MnSO}_{4}, \mathrm{ZnSO}_{4} \cdot 7 \mathrm{H}_{2} \mathrm{O}, \mathrm{Cr}_{2}\left(\mathrm{SO}_{4}\right)_{3} \cdot 15 \mathrm{H}_{2} \mathrm{O}, \mathrm{CoSO}_{4} \cdot 7 \mathrm{H}_{2} \mathrm{O}$, $\mathrm{NiSO}_{4} \cdot 6 \mathrm{H}_{2} \mathrm{O}$, and $\mathrm{CuSO}_{4} \cdot 5 \mathrm{H}_{2} \mathrm{O}$, the $\mathrm{K}_{2} \mathrm{~S}_{2} \mathrm{O}_{3}$ was significantly lower than others with all mixing ratios of standard to $\mathrm{BN}(P<0.05)$.

\subsection{Particle Size Effect on Sulfur K-Edge XANES Spectra} Sensitivity in Urban Aerosol. Recent studies have shown that the analysis of chemical speciation in aerosol can be conducted by using XANES technique [27-30]. However, only four studies have been examining sulfur K-edge XANES spectra in aerosol [31-33]. As shown in Figure 2, sulfur Kedge XANES spectra are obtained for both TSP and $\mathrm{PM}_{10}$ samples collected at Bangkok, Chiang-Mai, and Hat-Yai. All XANES spectra exhibited very strong symmetric peaks around $2,482 \mathrm{eV}$ and shoulders nearby $2,485 \mathrm{eV}$. Generally, the aerosols examined produced less signals in the TSP mode compared with the $\mathrm{PM}_{10}$ mode. This can be explained 
TABLE 2: Signal-to-noise ratios $(\mathrm{S} / \mathrm{N})$ of $\left(\mathrm{NH}_{4}\right)_{2} \mathrm{SO}_{4}, \mathrm{CaSO}_{4}, \mathrm{Al}\left(\mathrm{SO}_{4}\right)_{3}, \mathrm{MnSO}_{4}, \mathrm{ZnSO}_{4} * 7 \mathrm{H}_{2} \mathrm{O}, \mathrm{K}_{2} \mathrm{~S}_{2} \mathrm{O}_{3}, \mathrm{Cr}_{2}\left(\mathrm{SO}_{4}\right)_{3} * 15 \mathrm{H}_{2} \mathrm{O}, \mathrm{CoSO}_{4} * 7 \mathrm{H}_{2} \mathrm{O}$, $\mathrm{NiSO}_{4} * 6 \mathrm{H}_{2} \mathrm{O}$, and $\mathrm{CuSO}_{4} * 5 \mathrm{H}_{2} \mathrm{O}$ detected by $\mathrm{GeD}$ and $\mathrm{LyD}$.

\begin{tabular}{|c|c|c|c|c|c|c|c|c|}
\hline \multirow{2}{*}{$\begin{array}{l}\text { Mixing ratio \% } \\
\text { (sample: } \mathrm{BN} \text { ) }\end{array}$} & Germanium & Germanium & Germanium & Germanium & Lytle & Lytle & Lytle & Lytle \\
\hline & 0.1 & 1.0 & 10.0 & 100.0 & 0.1 & 1.0 & 10.0 & 100.0 \\
\hline $\mathrm{Al}_{2}\left(\mathrm{SO}_{4}\right)_{3}$ & 4.296 & 3.837 & 3.241 & 2.642 & 4.529 & 3.935 & 3.440 & 3.020 \\
\hline $\mathrm{CaSO}_{4}$ & 3.719 & 3.801 & 3.213 & 2.984 & 3.969 & 3.731 & 3.424 & 2.951 \\
\hline $\mathrm{ZnSO}_{4}$ & 3.650 & 3.598 & 2.893 & 2.714 & 3.532 & 3.640 & 3.056 & 2.894 \\
\hline $\mathrm{NiSO}_{4}$ & 4.308 & 3.965 & 3.334 & 3.136 & 4.196 & 4.145 & 3.503 & 3.385 \\
\hline $\mathrm{NH}_{4} \mathrm{SO}_{4}$ & 4.711 & 2.745 & 2.509 & 1.581 & 4.553 & 2.560 & 2.643 & 1.923 \\
\hline $\mathrm{K}_{2} \mathrm{~S}_{2} \mathrm{O}_{3}$ & 2.431 & 2.345 & 1.868 & 1.593 & 3.582 & 2.399 & 2.264 & 1.892 \\
\hline $\mathrm{FeSO}_{4}$ & 3.936 & 3.551 & 3.216 & 3.021 & 3.778 & 3.749 & 3.409 & 3.132 \\
\hline $\mathrm{CuSO}_{4}$ & 4.301 & 4.022 & 3.483 & 3.100 & 4.027 & 4.229 & 3.660 & 3.407 \\
\hline $\mathrm{CrSO}_{4}$ & 4.120 & 4.021 & 3.539 & 2.915 & 3.865 & 4.033 & 3.633 & 3.074 \\
\hline $\mathrm{CoSO}_{4}$ & 4.212 & 3.810 & 3.348 & 3.144 & 4.333 & 4.032 & 3.241 & 3.203 \\
\hline Average & 3.968 & 3.569 & 3.064 & 2.683 & 4.036 & 3.645 & 3.227 & 2.888 \\
\hline Stdev \% & 15.7 & 16.0 & 16.9 & 22.4 & 9.0 & 17.6 & 14.0 & 18.8 \\
\hline
\end{tabular}

by the signal damping caused by self-absorption effect of large particle as mentioned previously in Section 3.1. This effect seems to have become less pronounced with decreasing particle size and thus enhancing the signal of $\mathrm{PM}_{10}$ in comparison with those of TSP. It is also worth to note that differences in sensitivity between the two aerosol modes became more distinct after normalizing the signal intensity with particle weight (see Figure 2). However, there was one exception to this finding. While $\mathrm{PM}_{10}$ mode yielded excellent sensitivity for Bangkok and Chiang-Mai aerosols, TSP mode provided a better signal intensity than $\mathrm{PM}_{10}$ mode for Hat-Yai samples. Although the reason for the "sensitivity conversion" is not readily apparent, there are several possibilities behind the issue.

Analytical results showed that the highest ionic concentrations in Bangkok aerosols were $\mathrm{SO}_{4}{ }^{2-}>\mathrm{NO}_{3}{ }^{-}>$ $\mathrm{K}^{+}>\mathrm{Ca}^{2+}$ and $\mathrm{SO}_{4}{ }^{2-}>\mathrm{Ca}^{2+}>\mathrm{NO}_{3}{ }^{-}>\mathrm{K}^{+}$for $\mathrm{PM}_{10}$ and TSP, respectively, whereas those of Chiang-Mai particles were following the decreasing order of $\mathrm{SO}_{4}{ }^{2-}>\mathrm{NO}_{3}{ }^{-}>$ $\mathrm{NH}_{4}{ }^{+}>\mathrm{K}^{+}$and $\mathrm{Ca}^{2+}>\mathrm{SO}_{4}{ }^{2-}>\mathrm{NO}_{3}{ }^{-}>\mathrm{K}^{+}$for $\mathrm{PM}_{10}$ and TSP in that order. Previous studies found that the coarse fraction of $\mathrm{SO}_{4}{ }^{2-}$ is generally in the form of gypsum $\left(\mathrm{CaSO}_{4}\right)$ reflecting the relatively high contribution of terrestrial dusts observed in Chiang-Mai TSP [34, 35]. More interestingly, sulfate was discovered as the most dominant ionic species in both types of aerosols. Since Bai-Yok Suite Hotel (i.e., Bangkok sampling site) is located in the heart of business area in Bangkok and therefore encompassed by main arteries for traffic into and out of the city center on a daily basis, it seems logical to ascribe the comparatively great input of sulfate and nitrate to vehicle exhaust emissions. Similarly, the reasonably pronounced influence of sulfate and nitrate in $\mathrm{PM}_{10}$ measured at Chiang-Mai was observed and thus emphasized the possibility that traffic emissions were plausibly main sources of airborne pollutants in fine particles of this city.

On the contrary, the highest contributions of Hat-Yai ionic species in TSP came from $\mathrm{Cl}^{-}>\mathrm{SO}_{4}{ }^{2-}>\mathrm{Na}^{+}>$
$\mathrm{Ca}^{2+}$, while those in $\mathrm{PM}_{10}$ were following the decreasing sequence of $\mathrm{SO}_{4}{ }^{2-}>\mathrm{Cl}^{-}>\mathrm{Na}^{+}>\mathrm{NO}_{3}{ }^{-}$. Since HatYai city is located only $30 \mathrm{~km}$ in the west side of coastline, it appears reasonable to presuppose the moderately high loads of $\mathrm{Na}^{+}$and $\mathrm{Cl}^{-}$observed in Hat-Yai aerosols as a result of sea salt aerosol production occurring above the Gulf of Thailand. The finding is comparable with prior evidence that $\mathrm{SO}_{4}{ }^{2-}$ steadily appears to account for $36 \%$ $\left(\mathrm{PM}_{10}\right)$ and $24 \%$ (TSP) by mass of the total WSIS [36]. Over the past three decades, several studies suggest that $\mathrm{SO}_{4}{ }^{2-}$ maritime aerosols in the nucleation mode can be principally generated by gas-to-particle conversion (GPC), which are triggered by photooxidation of sulfur containing precursor gaseous species such as $\mathrm{SO}_{2}, \mathrm{H}_{2} \mathrm{~S}, \mathrm{CS}_{2}, \mathrm{COS}$, $\mathrm{CH}_{3} \mathrm{SCH}_{3}$, and $\mathrm{CH}_{3} \mathrm{SSCH}_{3}[37,38]$. The highest mass percentage of particulate $\mathrm{SO}_{4}{ }^{2-}$ was detected in Hat-Yai TSP with the value of $22.8 \%$, which exceeded those of Bangkok (10.6\%) and Chiang-Mai (5.0\%) for 2.2 and 4.6 times, respectively. Similarly, the highest mass percentage of $\mathrm{SO}_{4}{ }^{2-}$ in fine aerosol was observed in Hat-Yai $\mathrm{PM}_{10}$ with the value of $18.4 \%$, which surpassed those of Bangkok (7.2\%) and Chiang-Mai (2.8\%) for 2.6 and 6.6 times correspondingly.

These results were in good agreement with the maximum absorption of Hat-Yai samples in sulfur K-edge XANES spectra detected at 2,482 eV for both TSP and $\mathrm{PM}_{10}$, highlighting the positive correlation between percentage contribution of particulate $\mathrm{SO}_{4}{ }^{2-}$ and XANES absorption. However, it is important to stress that the ratios of $\mathrm{SO}_{4}{ }^{2-}-\mathrm{PM}_{10} / \mathrm{SO}_{4}{ }^{2-}$ TSP showed the reverse sequence against those of $\mathrm{SO}_{4}{ }^{2-}$ mass percentages. Interestingly, the ratios of $\mathrm{SO}_{4}{ }^{2-}-\mathrm{PM}_{10} / \mathrm{SO}_{4}{ }^{2-}$ TSP were following the decreasing order of Chiang-Mai > Bangkok > Hat-Yai, suggesting that Hat-Yai aerosols were overwhelmed with contribution of $\mathrm{SO}_{4}{ }^{2-}$ in TSP mode rather than $\mathrm{PM}_{10}$ mode. Hence, it seems reasonable to ascribe the "sensitivity conversion" in sulfur K-edge XANES spectra as a consequence of sulfate enrichment found in HatYai TSP. 

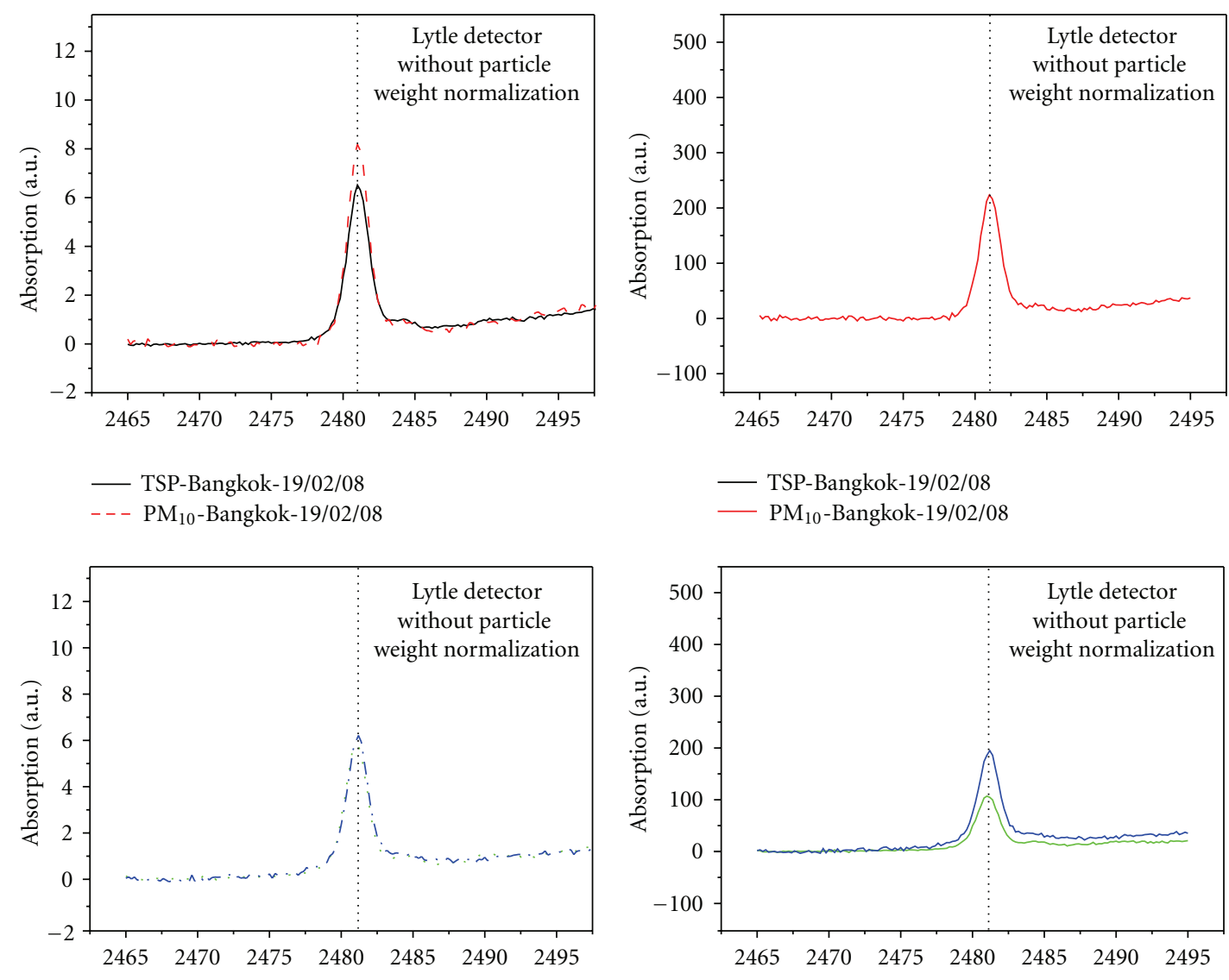

TSP-Chiang-Mai-26/02/08

-.. $\mathrm{PM}_{10}$-Chiang-Mai-26/02/08
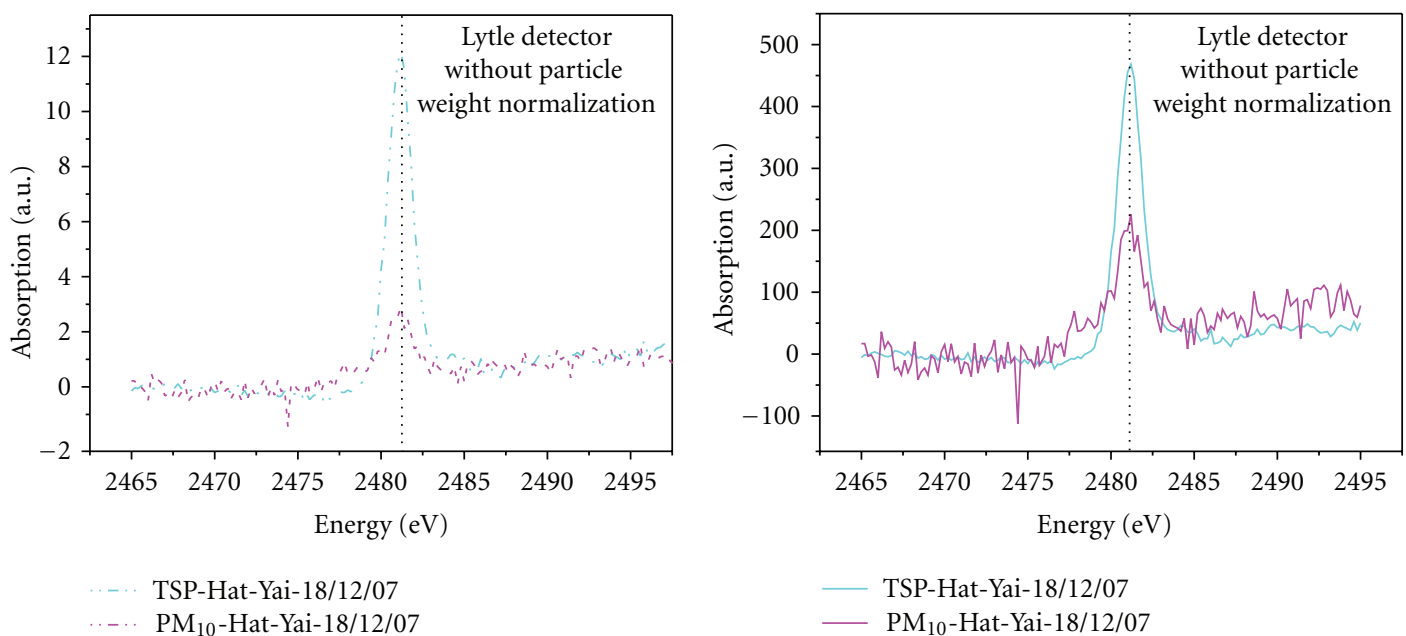

Figure 2: Comparison of sulfur K-edge XANES spectrum of urban aerosol collected at Bangkok, Chiang-Mai, and Hat-Yai measured by Lytle detector with and without particle weight normalization.

3.3. Variations of Sulfur K-Edge XANES Spectra in Different Soil and Sediment Types. The great Indian Ocean tsunami of December 26, 2004 was responsible for an estimated 250,000 of deaths and destroyed the coastal regions of the Indian Ocean nations. The December 26 tsunami is widely considered as the worst natural disaster to ever strike Thailand and thus has already provided traumatic impacts not only to the victims, but also to the scientists, policy makers, government officers, and several national and international organizations. Despite equitably large number of publications associated with several impacts of 2004 Indian Ocean tsunami on shore, little is known about the 
geochemical information of tsunami backwash deposits off shore [39-42]. Since the chemical composition records of tsunami deposits are greatly significant for the studies of both modern and past tsunami episodes, it should be of great interest to discriminate between the "typical marine sediment (TMS)" and "tsunami backwash deposit (TBD)."

It was reported that the sulfur K-edge XANES spectra can be used as a "fingerprint" to characterize different types of soils $[43,44]$. Thus it seems reasonable to assume that the sulfur K-edge XANES spectra can be used as a proxy to distinguish TBD from TMS. To test this hypothesis, five TMS and five TBD coupled with 16 German terrestrial soils were analyzed by the sulfur K-edge XANES in fluorescence mode as illustrated in Figure 5. The sulfur K-edge XANES spectra recorded from TMS and TBD in the present study generally showed the presence of several strong white lines at the energy level of $2,482 \mathrm{eV}$, indicating the existence of electronic oxidation state of +6 , which included inorganic and ester sulfates in marine sediments. The comparatively high involvement of sulfate species in sediment is in good agreement with those reported by previous studies in Jellyfish Lake, Palau, and Oman Margin sediments [45, 46]. Interestingly, the 16 German terrestrial soils studied fluctuated noticeably in the relative proportions of the two major absorption bands in the energy ranges of 2,467-2,472 eV (i.e., the energy range of reduced oxidation state) and 2,479$2,483 \mathrm{eV}$ (i.e., the energy range of oxidation state), signifying the occurrence of several oxidation states of $S$ in the target terrestrial soils (Figure 3). Since oxidation state plays a major role in determining the electronic and physicochemical properties of sulfur species, as it exists in combination with a group of one or more other elements, the complicated $S$ oxidation states emphasize the variety of sulfur speciation in terrestrial soil samples.

With the purpose of applying the sulfur K-edge XANES spectra as an innovative "fingerprint" to discriminate TBD from TMS, hierarchical cluster analysis (HCA) was performed by using average linkage clustering. The results demonstrated in the dendrogram (Figure 4) distinguished the 26 individual sulfur K-edge XANES spectra of marine sediments and terrestrial soil samples into two major clusters. The first major cluster (i.e., Cluster I) comprised of samples No. 53, No. 55, No. 71, No. 61, No. 49, No. 20, No. 34, No. 77, No. 48 , and No. 36 , which can be considered as an indicative of mixing of "TBD" and "TMS." Two major sediment types could be categorized from data similarities in line found in Cluster I. The first sediment group was characterized by samples No. 53, No. 55, No. 71, No. 61, No. 49, and No. 20 that can be considered as typical marine sediments except for sample No.71. The second one contained samples No. 34, No. 77 , No. 48 , and No. 36 , which may be produced by the backwash of tsunami terrestrial deposits.

In order to get further insights into the sample categorization of the remaining clusters, individual dendrogram distribution of German terrestrial soils was further plotted and illustrated in Figure 4. The second major cluster (i.e., Cluster II) can be subdivided into two subclusters. The first subcluster consisted of A-Bv, B-H1, B-H2, B-Aeh, A-Of, A-Oh, A-Aeh, which were all collected at sampling site of
Schlöppnerbunnen in Germany. Therefore, this subcluster represented the typical marks of Endostagnic, Leptic Cambisol (alumic), and Histic Stagnosol (albic, alumic). The second subcluster contained DH3, DH4, C-H2, C-Aa, which were found predominantly in Leptic Rheic Hemic Histosol (dystric). It was found that Cluster III was occupied by $\mathrm{C}$ Gr, D-H2, D-Go, B-Srw, and C-H1, indicating the mixture of Histic Stagnosol (albic, alumic) and Leptic Rheic Hemic Histosol (dystric). Overall, HCA successfully discriminated the sulfur K-edge XANES spectra of marine sediments from those of terrestrial soils as displayed in Figure 4.

Obviously, this dendrogram is quite useful and provides valuable information to identify the differences between marine sediments and terrestrial soils. However, this dendrogram, as well as sulfur K-edge XANES spectra, should be analyzed with great caution as oxidation process coupled with microbiological activity can alter oxidation state of $S$ during their transport from the sampling site to the analytical laboratory. With the intention of minimizing the above-mentioned uncertainties, principal component analysis (PCA) as the multivariate analytical tool was employed to reduce a set of original variables (i.e., measured sulfur K-edge XANES spectra in sediment and soil samples) and to extract a small number of latent factors (principal components (PCs)) for analyzing relationships among the observed variables. Data submitted for the analysis were arranged in a matrix, where each column corresponds to the number of sample and each row represents the absorption intensity of sulfur Kedge XANES spectra. Data matrixes were evaluated through PCA allowing the summarized data to be further analyzed and plotted.

With the aim of providing further interpretation of sulfur K-edge XANES spectra as sample fingerprints, a PCA model with three significant PCs, each representing 75.9\%, 16.3\%, and $4.52 \%$ of the variance, thus accounting for $96.7 \%$ of the total variation in the data, was calculated. After plotting factor scores of PC1, PC2, and PC3 in three dimensions, some distinctive features of data clustering were appeared. Firstly, 3D plots of Endostagnic, Leptic Cambisol (alumic), Histic Stagnosol (albic, alumic), and Leptic Rheic Hemic Histosol (dystric) are highly deviated from the Andaman coastal sediments in both TMS and TBD as illustrated in Figure 5(a). Secondly, a grouping of 3D plots of Andaman marine sediments can be further separated into two groups, which are (1) samples No. 20, No. 34, No. 36, No. 48, No. 49 (i.e., TMS) and (2) samples No. 53, No. 55, No. 61, No. 71, No. 77 (i.e., TBD) as displayed in Figure 5(b). As a consequence, it appears rationale to conclude that the combination of HCA and PCA could successfully distinguish German terrestrial soils from Andaman marine sediments, and thus enhancing the reliability of employing the sulfur Kedge XANES spectra as a new "fingerprint" to characterize environmental samples.

\section{Conclusions}

Generally, XANES spectra of $\left(\mathrm{NH}_{4}\right)_{2} \mathrm{SO}_{4}, \mathrm{CaSO}_{4}, \mathrm{Al}_{2}\left(\mathrm{SO}_{4}\right)_{3}$, $\mathrm{MnSO}_{4}, \quad \mathrm{ZnSO}_{4} \cdot 7 \mathrm{H}_{2} \mathrm{O}, \quad \mathrm{K}_{2} \mathrm{~S}_{2} \mathrm{O}_{3}, \quad \mathrm{Cr}_{2}\left(\mathrm{SO}_{4}\right)_{3} \cdot 15 \mathrm{H}_{2} \mathrm{O}$, 

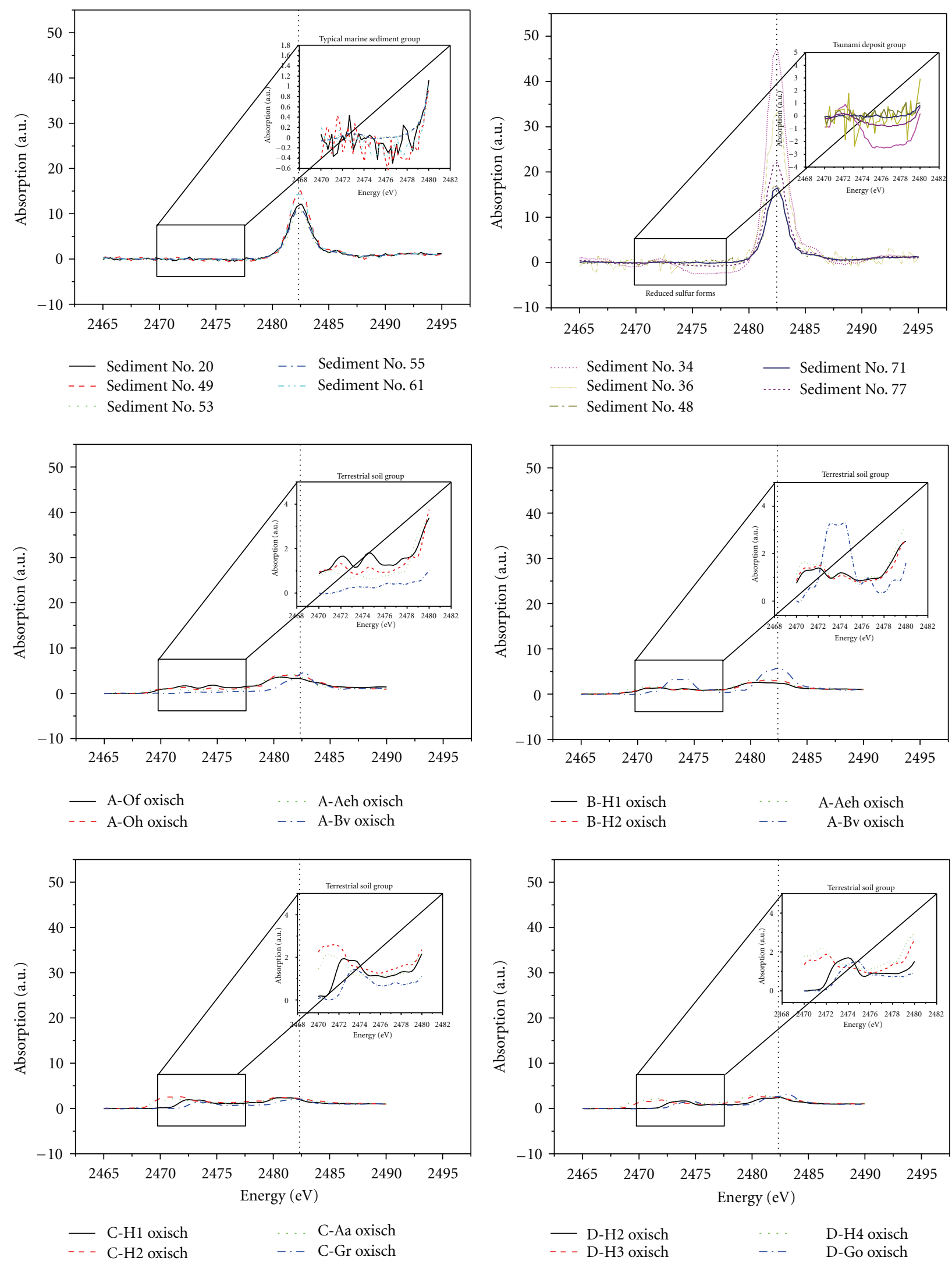

FIGURE 3: Sulfur K-edge XANES spectrum of typical marine sediment (TMS), tsunami backwash deposit (TBD), and German terrestrial soil (GS). 
Dendrogram using average linkage (between groups)

Rescaled distance cluster combine

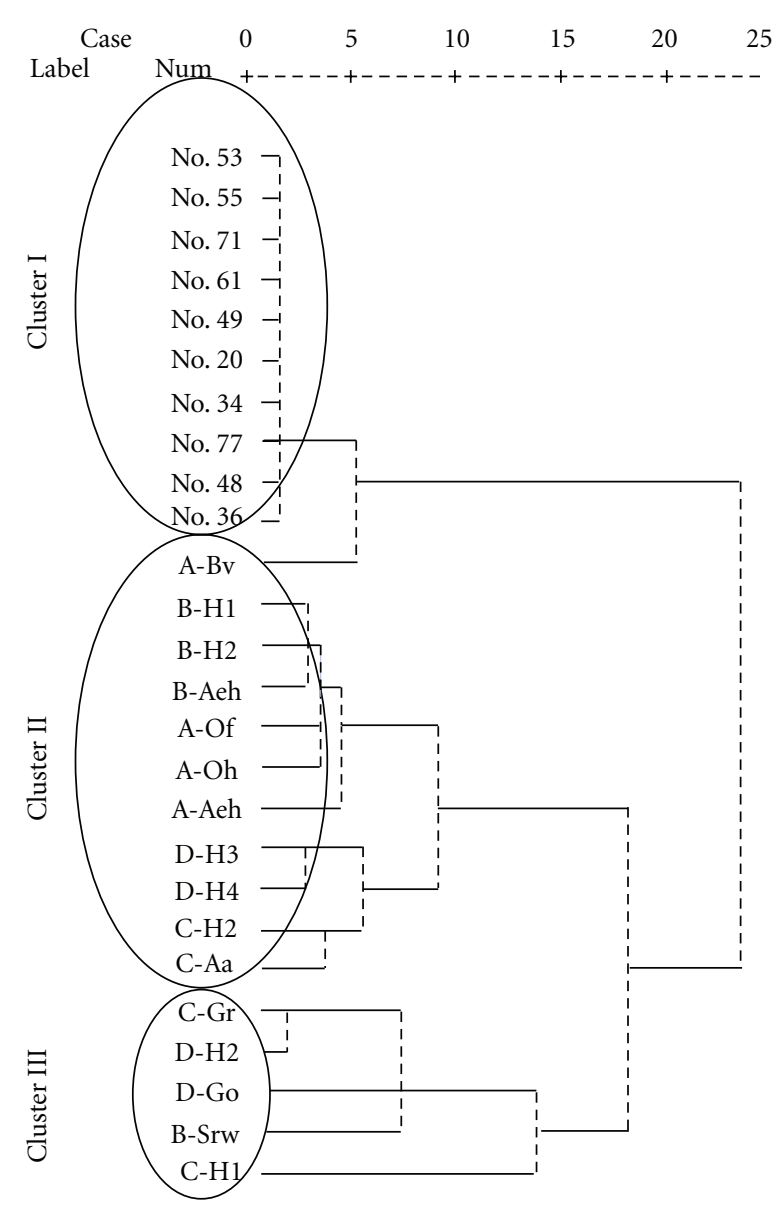

Figure 4: Dendrogram using average linkage (between groups) of Sulfur K-edge XANES spectrum of typical marine sediments (TMS), tsunami backwash deposits (TBD), and German terrestrial soils (GS).

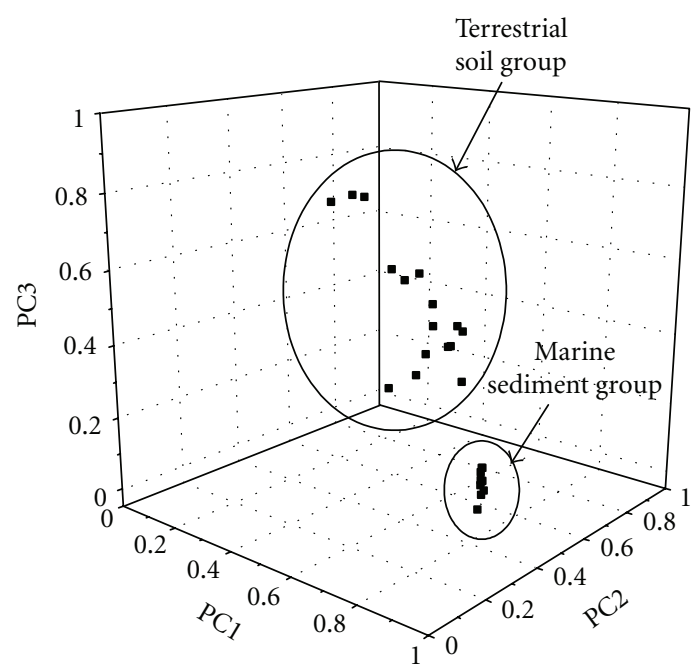

(a)

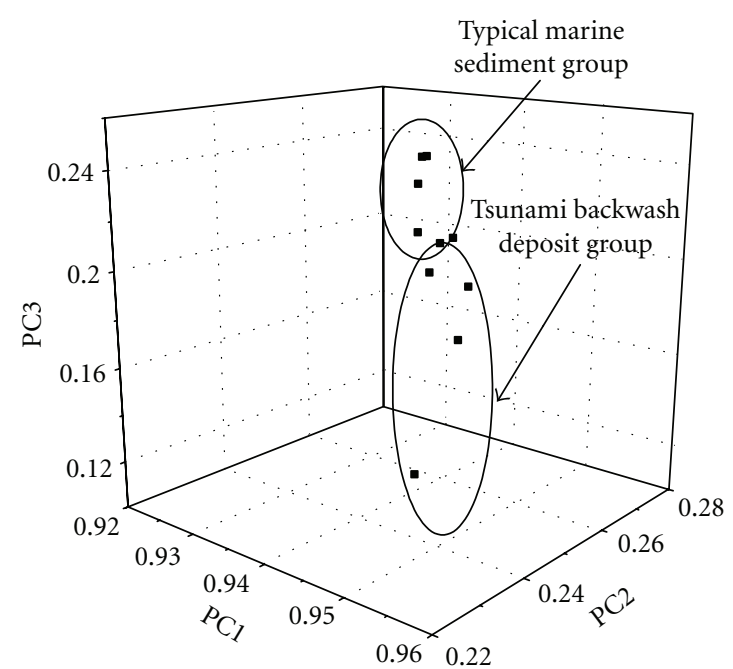

(b)

FIGURE 5: Three dimensional plots of principal component 1 (PC1), principal component 2 (PC2), and principal component 3 (PC3) of sulfur K-edge XANES spectrum of typical marine sediments (TMS), tsunami backwash deposits (TBD), and German terrestrial soils (GS). 
$\mathrm{CoSO}_{4} \cdot 7 \mathrm{H}_{2} \mathrm{O}, \mathrm{NiSO}_{4} \cdot 6 \mathrm{H}_{2} \mathrm{O}$, and $\mathrm{CuSO}_{4} \cdot 5 \mathrm{H}_{2} \mathrm{O}$ standards indicated that better sensitivity could be achieved in both detectors with mixing ratios of standard to $\mathrm{BN}$ at $0.1 \%$. There were no significant differences in term of instrumental sensitivity detected by both Lytle and Germanium detectors. Further investigation was conducted to assess the sensitivities of sulfur K-edge XANES spectra as functions of atmospheric particle sizes. For urban aerosols, the $\mathrm{S} / \mathrm{N}$ ratios of sulfur K-edge XANES spectra are anticorrelated with atmospheric particle sizes. However, this concept cannot be applied to sulfate-rich coarse particle-like maritime TSP. This study has proved that the sensitivities of sulfur K-edge XANES spectra were positively correlated with sulfate content in particles and negatively associated with atmospheric particle sizes. In addition, the combination of advanced statistical methods such as HCA and PCA evidently separated German terrestrial soils from Andaman marine sediment, and moderately distinguished typical marine sediments from tsunami backwash deposits.

\section{Acknowledgments}

This work has been performed with the approval of Synchrotron Light Research Institute (Public Organization). This study was bilaterally supported by the National Research Council of Thailand (NRCT) and the German Research Foundation (DFG) under the project entitled "Tsunami deposits in near-shore and coastal waters of Thailand (TUNWAT), Grant code: SCHW 572/11-1.” A support from Institute of Earth Environment, Chinese Academy of Sciences (IEECAS), National Institute of Development Administration (NIDA), and National Center of Excellence for Environmental and Hazardous Waste Management, Chulalongkorn University is also acknowledged.

\section{References}

[1] X. Q. Shan, B. Chen, T. H. Zhang, F. L. Li, B. Wen, and J. Qian, "Relationship between sulfur speciation in soils and plant availability," Science of the Total Environment, vol. 199, no. 3, pp. 237-246, 1997.

[2] J. T. Kiehl and B. P. Briegleb, "The relative roles of sulfate aerosols and greenhouse gases in climate forcing," Science, vol. 260, no. 5106, pp. 311-314, 1993.

[3] R. J. Chalrson and S. E. Schwartz, "Climate forcing by anthropogenic aerosols," Science, vol. 255, no. 5043, pp. 423430, 1992.

[4] W. P. Robarge, J. T. Walker, R. B. McCulloch, and G. Murray, "Atmospheric concentrations of ammonia and ammonium at an agricultural site in the southeast United States," Atmospheric Environment, vol. 36, no. 10, pp. 1661-1674, 2002.

[5] S. Beike, "Acid deposition: an updated review on atmospheric physico-chemical aspects of the acid deposition problem in Europe," CEC Publ. AP/53/85, 27, 1985.

[6] G. Zhou and K. Tazaki, "Seasonal variation of gypsum in aerosol and its effect on the acidity of wet precipitation on the Japan Sea side of Japan," Atmospheric Environment, vol. 30, no. 19, pp. 3301-3308, 1996.

[7] Y. J. Zhu, N. Olson, and T. P. Beebe, "Surface chemical characterization of $2.5-\mu \mathrm{m}$ particulates $\left(\mathrm{PM}_{2.5}\right)$ from air pollution in salt lake city using TOF-SIMS, XPS, and FTIR," Environmental Science \& Technology, vol. 35, no. 15, pp. 31133121, 2001.

[8] T. C. Xiao, W. X. Liu, H. T. Liu, and S. R. Wang, "Analysis on the Character of Atmospheric Particulates from Different Pollution Sources in Jinan City," Environmental Chemistry, vol. 17, p. 582, 1998.

[9] J. S. Pastuszka, A. Wawroś, E. Talik, and K. T. Paw, “Optical and chemical characteristics of the atmospheric aerosol in four towns in southern Poland," Science of the Total Environment, vol. 309, no. 1-3, pp. 237-251, 2003.

[10] I. J. Pickering, G. N. George, E. Y. Yu et al., "Analysis of sulfur biochemistry of sulfur bacteria using X-ray absorption spectroscopy," Biochemistry, vol. 40, no. 27, pp. 8138-8145, 2001.

[11] P. Feldens, K. Schwarzer, W. Szczuciński, K. Stattegger, D. Sakuna, and P. Somgpongchaiykul, "Impact of 2004 tsunami on seafloor morphology and offshore sediments, Pakarang Cape, Thailand," Polish Journal of Environmental Studies, vol. 18, no. 1, pp. 63-68, 2009.

[12] J. Prietzel, N. Tyufekchieva, K. Eusterhues et al., "Anoxic versus oxic sample pretreatment: effects on the speciation of sulfur and iron in well-aerated and wetland soils as assessed by X-ray absorption near-edge spectroscopy (XANES)," Geoderma, vol. 153, no. 3-4, pp. 318-330, 2009.

[13] W. Klysubun, P. Sombunchoo, N. Wongprachanukul et al., "Commissioning and performance of X-ray absorption spectroscopy beamline at the Siam Photon Laboratory," Nuclear Instruments and Methods in Physics Research A, vol. 582, no. 1, pp. 87-89, 2007.

[14] R. Chauvistré, J. Hormes, E. Hartmann, N. Etzenbach, R. Hosch, and J. Hahn, "Sulfur K-shell photoabsorption spectroscopy of the sulfanes R-Sn-R, $\mathrm{n}=2-4$," Chemical Physics, vol. 223, no. 2-3, pp. 293-302, 1997.

[15] M. Newville, "IFEFFIT: interactive XAFS analysis and FEFF fitting," Journal of Synchrotron Radiation, vol. 8, no. 2, pp. 322$324,2001$.

[16] E. H. Shaban, D. P. Siddons, and A. Kuczewski, "Gas electron multiplier (GEM) enhanced ionization chamber for fluorescence detector," Nuclear Instruments and Methods in Physics Research A, vol. 582, no. 1, pp. 185-186, 2007.

[17] P. Sangsingk, K. D. Berry, E. J. Dumas, T. W. Raudorf, and T. A. Underwood, "Advances in germanium detector technology," Nuclear Instruments and Methods in Physics Research A, vol. 505, no. 1-2, pp. 183-186, 2003.

[18] Y. Takahashi, Y. Kanai, H. Kamioka et al., "Speciation of sulfate in size-fractionated aerosol particles using sulfur K-edge X-ray absorption near-edge structure," Environmental Science and Technology, vol. 40, no. 16, pp. 5052-5057, 2006.

[19] F. E. Huggins, G. P. Huffman, and J. D. Robertson, "Speciation of elements in NIST particulate matter SRMs 1648 and 1650," Journal of Hazardous Materials, vol. 74, no. 1-2, pp. 1-23, 2000.

[20] H. Sekiyama, N. Kosugi, H. Kuroda, and T. Ota, "Sulfur Kedge absorption spectra of $\mathrm{Na}_{2} \mathrm{SO}_{4}, \mathrm{Na}_{2} \mathrm{SO}_{3}, \mathrm{Na}_{2} \mathrm{~S}_{2} \mathrm{O}_{3}$, and $\mathrm{Na}_{2} \mathrm{~S}_{2} \mathrm{O}_{x}(\mathrm{x}=5-8)$," Bulletin of the Chemical Society of Japan, vol. 59, no. 2, pp. 575-579, 1986.

[21] S. C. M. Myneni, "Soft X-ray spectroscopy and spectromicroscopy studies of organic molecules in the environment," Reviews in Mineralogy and Geochemistry, vol. 49, no. 1, pp. 485-579, 2002.

[22] X. Zhang, H. Ade, C. Jacobsen et al., "Micro-XANES: chemical contrast in the scanning transmission X-ray microscope," Nuclear Instruments and Methods in Physics Research A, vol. 347, no. 1-3, pp. 431-435, 1994. 
[23] W. F. Pong, Y. K. Chang, H. H. Hsieh et al., "Electronic and atomic structures of Si-C-N thin film by X-ray-absorption spectroscopy," Journal of Electron Spectroscopy and Related Phenomena, vol. 92, no. 1-3, pp. 115-118, 1998.

[24] Y. Takahashi, T. Miyoshi, S. Yabuki, Y. Inada, and H. Shimizu, "Observation of transformation of calcite to gypsum in mineral aerosols by Ca K-edge X-ray absorption near-edge structure (XANES)," Atmospheric Environment, vol. 42, no. 26, pp. 6535-6541, 2008.

[25] G. Falkenberg, G. Pepponi, C. Streli, and P. Wobrauschek, "Comparison of conventional and total reflection excitation geometry for fluorescence X-ray absorption spectroscopy on droplet samples," Spectrochimica Acta B, vol. 58, no. 12, pp. 2239-2244, 2003.

[26] F. Meirer, G. Pepponi, C. Streli et al., "Application of synchrotron-radiation-induced TXRF-XANES for arsenic speciation in cucumber (Cucumis sativus L.) xylem sap," $X$ Ray Spectrometry, vol. 36, no. 6, pp. 408-412, 2007.

[27] Y. Takahashi, T. Miyoshi, S. Yabuki, Y. Inada, and H. Shimizu, "Observation of transformation of calcite to gypsum in mineral aerosols by Ca K-edge X-ray absorption near-edge structure (XANES)," Atmospheric Environment, vol. 42, no. 26, pp. 6535-6541, 2008.

[28] J. Osán, F. Meirer, V. Groma et al., "Speciation of copper and zinc in size-fractionated atmospheric particulate matter using total reflection mode X-ray absorption near-edge structure spectrometry," Spectrochimica Acta B, vol. 65, no. 12, pp. 1008 $1013,2010$.

[29] U. E. A. Fittschen, F. Meirer, C. Streli et al., "Characterization of atmospheric aerosols using Synchroton radiation total reflection X-ray fluorescence and Fe K-edge total reflection X-ray fluorescence-X-ray absorption near-edge structure," Spectrochimica Acta B, vol. 63, no. 12, pp. 1489-1495, 2008.

[30] C. Streli, G. Pepponi, P. Wobrauschek et al., "Recent results of synchrotron radiation induced total reflection X-ray fluorescence analysis at HASYLAB, beamline L," Spectrochimica Acta $B$, vol. 61, no. 10-11, pp. 1129-1134, 2006.

[31] S. Frisia, A. Borsato, I. J. Fairchild, and J. Susini, "Variations in atmospheric sulphate recorded in stalagmites by synchrotron micro-XRF and XANES analyses," Earth and Planetary Science Letters, vol. 235, no. 3-4, pp. 729-740, 2005.

[32] F. Cozzi, I. Pellegrini, G. Adami, E. Reisenhofer, M. Bovenzi, and P. Barbieri, "Sulphur speciation of PM10 samples by XANES spectroscopy," Central European Journal of Chemistry, vol. 7, no. 3, pp. 395-401, 2009.

[33] M. Higashi and Y. Takahashi, "Detection of S(IV) species in aerosol particles using XANES spectroscopy," Environmental Science \& Technology, vol. 43, no. 19, pp. 7357-7363, 2009.

[34] S. Henning, E. Weingartner, M. Schwikowski et al., "Seasonal variation of water-soluble ions of the aerosol at the high-alpine site Jungfraujoch (3580 m asl)," Journal of Geophysical Research $D$, vol. 108, no. 4030, 10 pages, 2003.

[35] G. Zhou and K. Tazaki, "Seasonal variation of gypsum in aerosol and its effect on the acidity of wet precipitation on the Japan Sea side of Japan," Atmospheric Environment, vol. 30, no. 19, pp. 3301-3308, 1996.

[36] J. A. Moralesa, D. Pirelab, M. G. Navaa, B. S. Borregoa, H. Velásqueza, and J. Durána, "Inorganic water soluble ions in atmospheric particles over Maracaibo Lake Basin in the western region of Venezuela," Atmospheric Research, vol. 46, no. 3-4, pp. 307-320, 1998.

[37] M. O. Andrea, "The emissions of sulfur to the remote atmosphere: background paper," in The Biogeochemical Cycling of Sulfur and Nitrogen in the Remote Atmosphere, J. N. Galloway,
R. I. Charlson, M. O. Andreae, and H. Rodhe, Eds., p. 5, Reidel, Dordrecht, The Netherlands, 1985.

[38] J. W. Fitzgerald, "Marine aerosols: a review," Atmospheric Environment A, vol. 25, no. 3-4, pp. 533-545, 1991.

[39] M. Choowong, N. Murakoshi, K. I. Hisada et al., "2004 Indian Ocean tsunami inflow and outflow at Phuket, Thailand," Marine Geology, vol. 248, no. 3-4, pp. 179-192, 2008.

[40] W. Szczuciński, P. Niedzielski, G. Rachlewicz et al., "Contamination of tsunami sediments in a coastal zone inundated by the 26 December 2004 tsunami in Thailand," Environmental Geology, vol. 49, no. 2, pp. 321-331, 2005.

[41] W. Szczuciński, N. Chaimanee, P. Niedzielski et al., "Environmental and geological impacts of the 26 December 2004 tsunami in coastal zone of Thailand-overview of short and long-term effects," Polish Journal of Environmental Studies, vol. 15, no. 5, pp. 793-810, 2006.

[42] A. Siripong, "Andaman seacoast of Thailand field survey after the december 2004 Indian ocean tsunami," Earthquake Spectra, vol. 22, supplement 3, pp. 187-202, 2006.

[43] J. Prietzel, J. Thieme, N. Tyufekchieva, D. Paterson, I. McNulty, and I. K. Knabner, "Sulfur speciation in well-aerated and wetland soils in a forested catchment assessed by sulfur k-edge x-ray absorption near-edge spectroscopy (xanes)," Journal of Plant Nutrition and Soil Science, vol. 172, no. 3, pp. 393-403, 2009.

[44] J. Prietzel, J. Thieme, M. Salomé, and H. Knicker, "Sulfur K-edge XANES spectroscopy reveals differences in sulfur speciation of bulk soils, humic acid, fulvic acid, and particle size separates," Soil Biology and Biochemistry, vol. 39, no. 4, pp. 877-890, 2007.

[45] A. L. Bates, E. C. Spikera, W. H. Orema, and W. C. Burnettb, "Speciation and isotopic composition of sulfur in sediments from Jellyfish Lake, Palau," Chemical Geology, vol. 106, no. 12, pp. 63-76, 1993.

[46] E. Lallier-Vergès, P. Bertrand, and A. Desprairies, "Organic matter composition and sulfate reduction intensity in Oman Margin sediments," Marine Geology, vol. 112, no. 1-4, pp. 5769, 1993. 


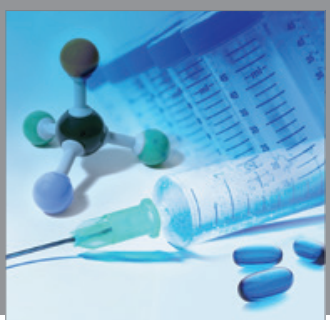

International Journal of

Medicinal Chemistry

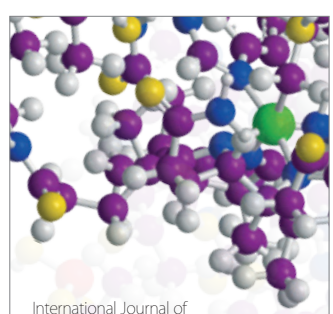

Carbohydrate Chemistry

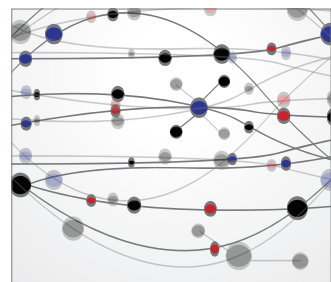

The Scientific World Journal
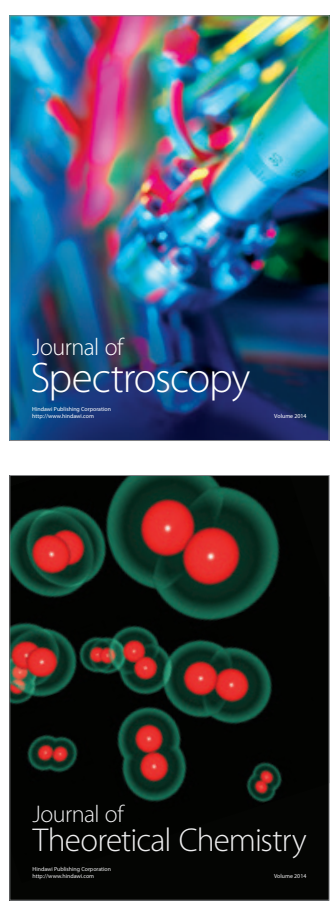
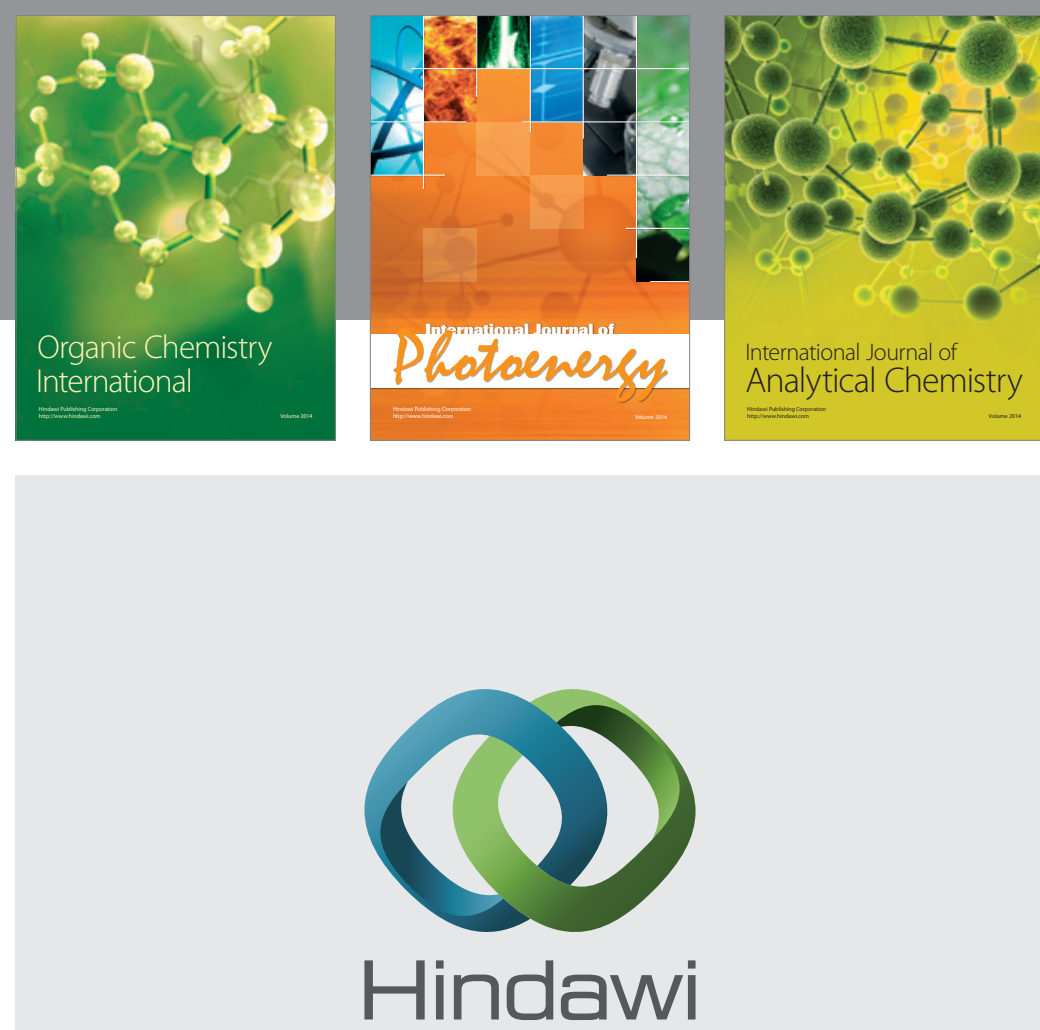

Submit your manuscripts at

http://www.hindawi.com
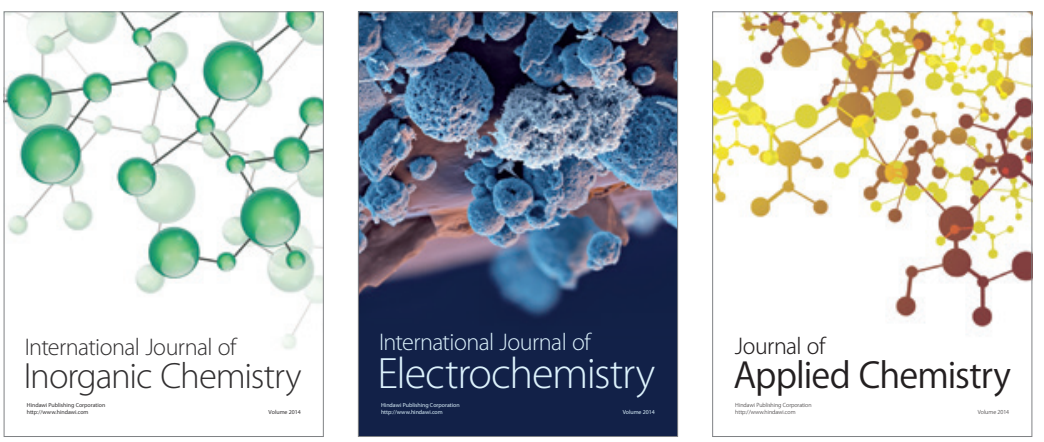

Journal of

Applied Chemistry
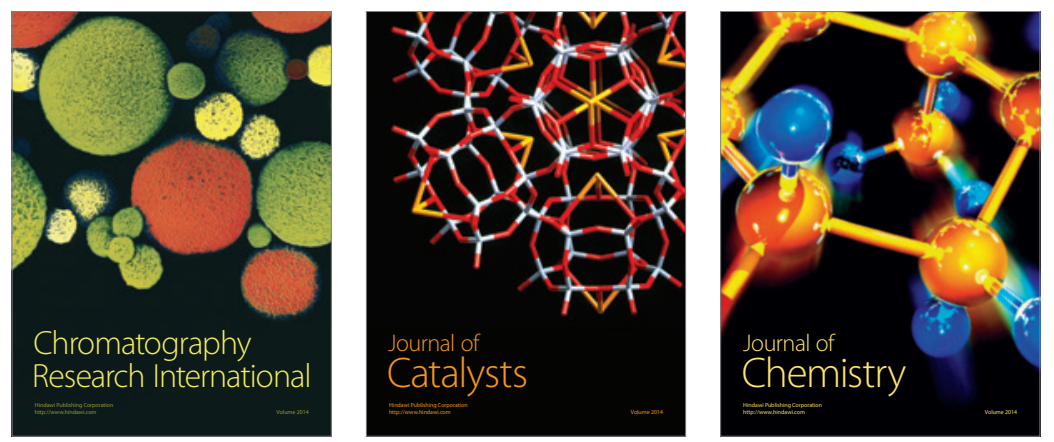
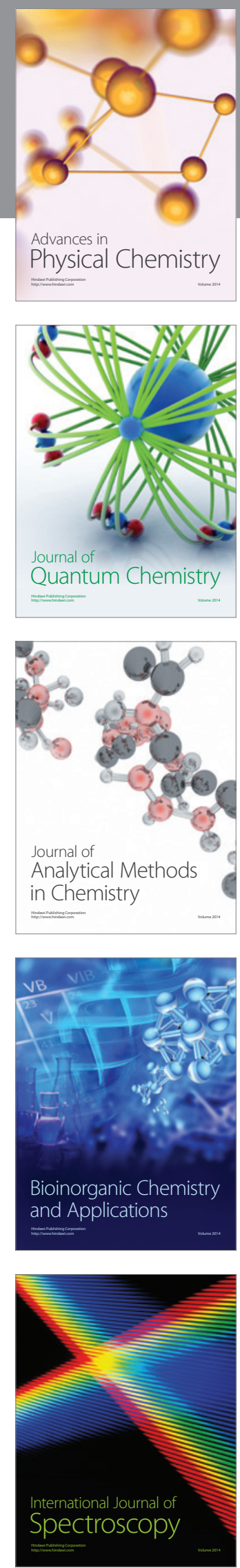